\title{
JUSTICIA RESTAURATIVA: UN NUEVO MODELO DE JUSTICIA EN MATERIA PENAL
}

\author{
Georgina Pesqueira Angulo ${ }^{36}$ \\ Germán Guillén López ${ }^{37}$ \\ El mérito auténtico es, pudiendo hacer daño, no hacerlo.
}

Siro

Sumario: I.Consideraciones previas II.Aproximación conceptual III. Principios que rigen a la Justicia Restaurativa IV. Función político-criminológica V. Conclusiones VI. Bibliografía.

\section{Resumen}

En el presente trabajo se contempla un análisis introductorio a la Justicia Restaurativa y la refutación a las concepciones erróneas que hay al respecto de la misma. Se harán consideraciones previas respecto al nacimiento de la misma en el contexto mexicano; posteriormente se discutirá la aproximación conceptual y los principios que la rigen. Este asentará las bases para discutir su función político-criminal y por qué cobra relevancia abordarla en la legislación.

Palabras clave: justicia restaurativa, conflicto, daño, reparación.

\begin{abstract}
An introduction to the key concepts of Restorative Justice in the Mexican Context is necessary to clarify the misconceptions that have surfaced over the past years, and in particular since the transition to a new Justice System was announced in 2008. A timeline, highlighting the most important events in contributions to Restorative Justice in modern times will be provided, as well as

\footnotetext{
${ }^{36}$ Estudiante de Doctorado en Derecho

37 Profesor Investigador de Tiempo Completo del Departamento de Derecho de la División de Ciencias sociales de la Universidad de Sonora Unidad Regional Centro
} 
the diverse concepts that apply. The above will set the stage to properly discuss the relevance and importance of political-criminal policy in this regard and why it is necessary to contemplate the regulation of it.

Keywords: restorative justice, conflict, reparation, injury.

\section{I.Consideraciones Previas}

La justicia restaurativa, tal y como hoy es conocida, conserva la esencia de su origen primario en los pueblos indígenas ${ }^{38}$. Hay referencias que en la antigüedad, en algunos colectivos humanos, el delito era considerado como un daño al individuo. Desde esa perspectiva, antiguos nativos de Norte América, Canadá, Australia y Nueva Zelanda, practicaron ciertos modos de justicia restaurativa fundamentados y orientados a la reparación del daño y la sanación de las heridas mediante la discusión e interacción directa entre víctimas, infractor y, en la mayoría de las ocasiones, la comunidad.

En épocas recientes, después de que varias tendencias doctrinales críticas al modelo de resolución de conflictos basado en una justicia penal represiva —durante décadas- habían señalado su notorio fracaso, estas antiguas formas de resolver contiendas entre particulares, a través de modelos de Justicia Restaurativa, comienzan a retomar presencia en el escenario internacional. En este sentido, en el Séptimo Congreso de las Naciones Unidas sobre Prevención del Delito y Justicia Penal (1985), que se llevó acabo en Milán, se retoma una idea sustancial: "Acceso a la Justicia y trato Justo."

En cierta medida, la prescripción de "Acceso a la Justicia y trato Justo" establece bases para transitar a un sistema de justicia restaurativa. Ya no era discutible, en ese momento, el despertar colectivo, la conciencia de las masas, en relación al hecho de que el fracaso del sistema penal retributivo -apoyado en colapsadas instituciones burocráticas- era real e inminente, lo que estimuló

\footnotetext{
${ }^{38}$ Van Ness, Daniel W. and Karen Heetderks Strong. Restoring justice: An introduction to restorative justice. Access Online via Elsevier, 2010.
} 
una emergente búsqueda de opciones distintas que fueran eficaces para afrontar el problema de la delincuencia.

En la misma perspectiva político-criminológica, para diciembre de 1990 se emitieron las Reglas de Tokio, que fomentaban un sentido de responsabilidad hacia la sociedad. Desde un contexto jurídico vinculatorio de trascendencia internacional la trilogía Víctima-Comunidad-Ofensor cobra mayor relevancia. En dicho documento, se considera a las integrantes del conflicto como realidades humanas sensibles — que tienen necesidades de reparación distinta a la que brinda la justicia punitiva.

El avance gradual de los postulados provenientes de la Justicia Restaurativa logra auge y presencia sin precedente en el Décimo congreso de las Naciones Unidas sobre Prevención del Delito y Justicia Penal (2000), ya que en éste se recomiendan planes de acción nacionales, regionales e internacionales que incluyan mecanismos de mediación y justicia restaurativa. Posteriormente, en la declaración de Costa Rica sobre la Justicia Restaurativa de América (2005), por fin se asientan las directrices a seguirse institucionalmente. Para el 2006, en Nueva York, fue entregado el Handbook on Restorative Justice Pogrammes, una introducción a la Justicia Restaurativa y los procesos y programas a considerarse dentro de la misma - este fue emitido por la Oficina de las Naciones Unidas contra la Droga y el Delito.

Las tendencias internacionales - principalmente las disposiciones en documentos de carácter vinculatorio- así como los imperiosos esfuerzos de especialistas nacionales -e institutos que durante años habían promovido a nivel nacional el tema-, concurren para que en México, en el 2007, el entonces Presidente Felipe Calderón, presentara la iniciativa de reforma en materia de seguridad y justicia que culmina en una profunda modificación al texto constitucional (2008) en áreas de justicia y política criminal, en la que, entre otras novedades, se contemplan mecanismos alternativos de solución de controversias (artículo 17 Constitucional). 
Otro factor que impulsó de forma contundente la construcción de un escenario que contemplara la Justicia Restaurativa, es que los órganos de decisión reconocieron que la Justicia estaba en riesgo y era preciso que se restablecieran ciertas instancias para poder transitar hacia un país seguro y pacífico. En este sentido, tales instancias están conscientes que este rescate solo se puede hacer a través de la reintegración del delincuente así como de la víctima, quien después de ser sometida a un proceso de actualización de un ilícito puede sentirse ajena a la sociedad, y a la comunidad misma.

Chihuahua, Sonora, Oaxaca y Nuevo León se convirtieron en pioneros en legislación de Justicia Restaurativa en los Estados. Posteriormente, otros estados han plasmado en sus legislaciones locales este camino alternativo a la resolución de conflictos. Se consideran, las necesidades de los intervinientes en el conflicto y se establece que se necesita comprender la causa del delito, promover el bienestar comunitario y prevenir la delincuencia.

\section{II.Aproximación conceptual}

Desde sus inicios, se rescata simplemente el ideal de enfocarse en las necesidades de la víctima y del ofensor. Tal vez esta sea una de las causas que han generado tan diversa amplitud a su significado, pues existen —en la bibliografía especializada - una diversidad de conceptos asignados, según el momento y el contexto.

John Brathwaite, en su obra Restorative Justice and De professionalization $^{39}$, explica que esta se entiende “... como un proceso donde todos las partes que se han visto afectadas por una injusticia tienen la oportunidad de discutir como es que se vieron afectadas y decidir que debería hacerse para reparar el daño. Más específicamente, respecto al ilícito, se postula la idea de que como el crimen lastima, la justicia debería sanar...". Sostiene que es favorable —en los casos que esto es posible — la realización de todas las conversaciones entre aquellos que han sido lastimados y aquellos

39 John Brathwaite, "Restorative Justice and De-Professionalization", The Good Society Volume 13, number 1 (2004) pp. 28-31. 
que han lastimado. Asimismo, afirma que esta parte es el núcleo del mismo proceso.

Desde la perspectiva pública, esta fórmula - a diferencia del sistema penal- procura que las necesidades de cada una de las partes intervinientes sean cubiertas en una atmósfera que contribuya a paz de la comunidad. El cambio de paradigma - esencialmente- se hace respecto a quién se ha visto ofendido o transgredido frente a la actualización de un ilícito. Lo que antes se contemplaba como pertinente al Estado, pasa a ser parte de la esfera de contención de los ciudadanos, de la comunidad, de la sociedad ${ }^{40}$.

En otro sentido, en el ámbito político-criminológico, puede ser entendida como una corriente del derecho penal de intervención mínima que integra en el ámbito adjetivo procesos voluntarios flexibles y transformativos en los que participan los protagonistas del conflicto criminal directa o subrogadamente, uno o varios facilitadores y cuando resulta necesario familiares, miembros de la comunidad e integrantes de instituciones públicas, privadas y sociales, con el fin de atender las necesidades de la víctima, del delincuente y de la comunidad, orientadas a su reintegración social. ${ }^{41}$

La justicia restaurativa no es simplemente un nuevo programa o una nueva técnica sino algo mucho más ambicioso: un cambio fundamental en la forma en que vemos y respondemos a el comportamiento criminal y problemático, y como nos relacionamos con quienes cometen estos actos y los que son afectados por los mismos. ${ }^{42}$ Por tal motivo, debe ser considerado un

40 Kathryn Blyss. "Restorative Justice and Public Opinion: The role of citizen, community and the state in justice." PhD diss., Saint Mary's University, 2013.

41 Jorge Pesqueira, "Conclusiones sobre el foro de análisis Dialéctico sobre Justicia Penal Restaurativa y salidas alternas al Juicio Oral", en Primer Congreso Nacional de Justicia Restaurativa y Oralidad, (Acapulco, Guerrero, 2010).

42 Margarita Zernova, "Restorative Justice Ideas, Values and Debates", Internet Journal of Criminology (2011 [citado el 25 de Noviembre del 2013]) disponible en:

http://www.internetjournalofcriminology.com/Zernova Book Review Restorativ e Justice IJC Feb 2012.pdf 
mecanismo de solución de controversias que va más allá de una solución de carácter superficial o administrativa.

Sigue habiendo mucho escepticismo, lo cual se deriva primariamente de la falta de entendimiento de lo que se quiere hacer. La Justicia restaurativa no es un premio, como muchos lo postulan. No es una manera sencilla —y fácilque apela a los criterios de oportunidad para permitir que quien ha actualizado un ilícito tenga una sustitución de la pena y que goce de no haber recibido ningún castigo. Es un sistema democrático de justicia que promueve la paz social $\mathrm{y}$, en consecuencia, la armonización de las relaciones intra e interpersonales dañadas por la conducta criminal; esto, a través de la solución auto compositiva de las necesidades de la víctima, de las obligaciones, la responsabilización genuina y las necesidades del ofensor, así como de las necesidades y compromisos asumidos por miembros o asociaciones de la comunidad. $^{43}$

Es necesario precisar, que esta nueva vía a la justicia, cubre una multitud de estancias: la compasión, el perdón, la curación, la misericordia, la reconciliación y cuando sea pertinente la sanción. También, que la misma postula una visión del mundo donde todos estamos interconectados y lo que hagamos, sea para el bien o para mal, tiene un impacto en los demás. Desde las víctimas, los delincuentes, las familias involucradas o la comunidad en general, todos tenemos que tener un papel en la solución de los problemas que se derivan de la delincuencia. ${ }^{44}$

\section{III.PRINCIPIOS QUE RIGEN LA JUSTICIA RESTAURATIVA}

\footnotetext{
${ }^{43}$ Rosalía Buenrostro, Jorge Pesqueira, y Miguel Ángel Soto LaMadrid. Justicia Alternativa y el Sistema Acusatorio (México: SEGOB, 2013).

${ }^{44} \mathrm{Jim}$ Consedine, Restorative justice: Healing the effects of crime. Lyttelton: Ploughshares Publications, 1995.
} 
Desde la doctrina ${ }^{45}$ se estipula que son doce los postulados que rigen todo el sistema de Justicia Restaurativa. Tales principios han sido descritos de forma precisa por Buenrostro, Pesqueira y Soto La Madrid, de la manera que presentan a continuación:

$1^{0}$ Voluntariedad. Entendiéndose como la manifestación de la voluntad respecto a la participación en el proceso. Esta se puede revocar en cualquier momento del proceso si alguna de las partes ha decidido no seguir más.

$2^{\circ}$ Confidencialidad. Implica que todo lo que se discuta y se hable será mantenido en el proceso. Este principio es de suma importancia porque permite a las partes abrirse al proceso y poder llevarlo con la tranquilidad de que no habrá represalias.

$3^{\circ}$ Imparcialidad. El facilitador al estar parcializado a una situación no será capaz de llevar a cabo una correcta guía y manejo de facilitación de la comunicación que deberá existir entre las partes; y, por otro lado, el efecto que un apercibimiento de parcialidad tiene en las partes y la manera en que llevaran a cabo el proceso.

$4^{\circ}$ Cooperación. Comprende que el propósito en común de ambos tiene que ser el alcanzar un resultado satisfactorio que no contemple la venganza, las ganas de lastimar, herir o hacer daño a la otra parte.

$5^{\circ}$ Creatividad. Elemento que debe estar presente debido a la gran complejidad de las situaciones delictivas - a veces es necesario buscar otras maneras de abordar la situación.

$6^{\circ}$ Honestidad. Es indispensable que el facilitador domine el conocimiento de sistemas de justicia retributivo, resocializador y restaurativo. Además, debe ser capaz de realizar un manejo eficaz de los procesos y conocer

45 Rosalía Buenrostro, Jorge Pesqueira, y Miguel Ángel Soto La Madrid. Justicia Alternativa y el Sistema Acusatorio (México: SEGOB, 2013). 
los valores que tutelan las figuras delictivas para entender la magnitud del daño cuya consumación ocasiona, tanto a las víctimas como a la comunidad.

$7^{0}$ Equidad. Existe ya implícitamente un desequilibrio en la relación de las partes. Se tiene que velar por ajustar eso.

$8^{\circ}$ Subrogación. No siempre se cuenta con la voluntariedad de ambas partes para someterse a un proceso, es por eso que se cuenta con la posibilidad de sustituir a una de las partes para que quien si tiene interés en participar en un proceso de restauración pueda encontrar consciencia, paz y satisfacción social.

$9^{\circ}$ Complementariedad. Tiene que haber una respuesta complementaria a las penas y medidas de seguridad que, hasta hace poco, constituían las únicas reacciones al delito.

$10^{\circ}$ Arrepentimiento. Es necesario que se presente el arrepentimiento por el ilícito actualizado, este no es espontaneo. Se alcanza después de someter a la parte a previos encuentros con el facilitador y hacer una cantidad sustancial de introspección así como concientización interna.

$11^{\circ}$ Responsabilidad. No implica una responsabilidad penal puesto que debe tenerse en cuenta que siempre prevalece el principio de presunción de inocencia ante las instancias judiciales, pero durante el proceso es vital que la parte asuma responsabilidad por lo que sucedió.

$12^{\circ}$ Satisfacción de necesidades. No solo tiene que haber una satisfacción por parte de la víctima y del victimario, sino que es ideal que haya una involucración por parte de la comunidad que también se ha visto afectada por el ilícito actualizado. 
La política criminal contemporánea indica que los beneficios de la Justicia Restaurativa $^{46}$ no tienen que limitarse solo a la practicidad de nuestro sistema acusatorio, sino que permiten, por ejemplo, su inclusión a los aspectos que tienen que ver con justicia para adolescentes en conflicto con la norma o en el ámbito penitenciario (Fungiendo como pieza clave para los índices de reincidencia y demarcando su último objetivo: paz social.).

En otro sentido, debe tomarse en cuenta que existen procedimientos distintos para atender las necesidades de respuesta, reconocimiento, seguridad y reparación que tienen las victimas y los ofendidos del delito. Aunque hay una priorización clara hacia quienes son víctimas en el esquema del suceso, es innegable que también hay un lugar para el delincuente y es ahí donde puede atender sus necesidades y lograrse posteriormente una reinserción social haciéndose de la mano de las demás disciplinas pertinentes ${ }^{47}$.

Aunado a lo señalado en el párrafo anterior, al involucrar a los miembros de la comunidad en este tipo de procesos, se busca el rescate de la víctima y que al delincuente le resulte alcanzable la comprensión de porque cometió el ilícito así como se pueda lograr la desestigmatizacion del mismo ante su comunidad. Es decir, la Justicia Restaurativa aporta una nueva visión de ciudadanía frente a la Seguridad Pública y proporciona elementos que se pueden convertir insumos al servicio de la construcción de una tangible la paz pública.

Desde otro enfoque, las salidas alternas a la audiencia del juicio oral y el procedimiento penal abreviado con enfoque restaurativo, auxilian a superar la cada vez más generalizada percepción de que el nuevo modelo de

${ }^{46}$ Costa Ferreira Carolina. "As Ilusões do Paradigma Punitivo E As Novas Perspectivas de Solução de Conflitos: A Justiça Restaurativa Como Caminho Possível À Crise do Sistema Penal Brasileiro." Revista de Estudos Jurídicos UNESP14, No. 19 (2011).

${ }^{47}$ Zehr, Howard. The Little Book Of Restorative Justice. Intercourse, Pa: Good Books, 2002. 
enjuiciamiento penal se ha mercantilizado o convertido en justicia blanda que solo favorece a los que más tienen. ${ }^{48}$

Para finalizar, se está en un estado precario frente a la necesidad del establecimiento de pactos para poder enfrentar y prevenir la criminalidad con una concepción humanística. ${ }^{49} \mathrm{Si}$ se atiende que los delitos son la manifestación del fracaso frente a un proceso de socialización, se puede empezar a buscar las respuestas al ilícito en una multitud de factores que pueden ser cambiados: la familia, el sistema educativo, la comunidad próxima y los demás agentes formales e informales.

\section{V.CONCLUSIONES}

Existen cinco puntos importantes que se desprenden de lo previamente expuesto.

i. La justicia restaurativa no es un invento de nuestro siglo, ni algo propuesto por un grupo particular. Es algo que tiene sus inicios en las primeras comunidades humanas y que no pierde de vista la diversidad de alternativas para afrontar una situación en donde se preocupa la Ley Penal.

ii. El proceso de la Justicia Restaurativa, busca un acercamiento entre las partes con el afán de satisfacer las necesidades de ambas respecto a las consecuencias de la actualización de un ilícito. Esta concepción no siempre indica que se otorga un Perdón, o una liberación, o que se hace un intercambio en la pena, este es un mito que no debe perpetuarse.

\footnotetext{
${ }^{48}$ Román Pinzón Edmundo, y Pesqueira Leal Jorge. "Manifiesto de Guerrero". En I Congreso Nacional de Justicia Restaurativa y Oralidad. (Acapulco, Guerrero, 2010)

49 Pesqueira Jorge, "Conclusiones sobre el foro de análisis Dialéctico sobre Justicia Penal Restaurativa y salidas alternas al Juicio Oral", en Primer Congreso Nacional de Justicia Restaurativa y Oralidad, (Acapulco, Guerrero, 2010).
} 
iii. Las finalidades de la Justicia Restaurativa, se alejan totalmente de lo que conocemos tradicionalmente como el sistema de Justicia Tradicional; el cambio de paradigma y perspectiva se hace respecto a lo que se ha conceptualizado en la Justicia Retributiva.

iv. Los principios que deben de regir, y que irán entreverándose y cobrando mayor o menor relevancia según la etapa en la que se encuentre, son los siguientes: Voluntariedad, Confidencialidad, Imparcialidad, Cooperación, Creatividad, Honestidad, Equidad, Subrogación, Complementariedad, Arrepentimiento, Responsabilidad y Satisfacción de necesidades.

v. Es un engranaje complementario a nuestro sistema de Justicia, su inclusión hace que este trabaje con mayor eficacia, con mayor potencia. Es relevante legislar al respecto.

La Justicia Restaurativa se aleja de los métodos donde se negocia y mercantiliza la Justicia; Son los cimientos para obtener una Paz en nuestras comunidades, en nuestras ciudades, en nuestro País.

\section{Bibliografía y Webgrafía}

Bliss, Kathryn. "Restorative Justice and Public Opinion: The role of citizen, community and the state in justice." PhD diss., Saint Mary's University, 2013.

Braithwaite, John, "Restorative Justice and De-Professionalization", The Good Society Volume 13, number 1 (2004) pp. 28-31.

Buenrostro, Rosalía, Pesqueira, Jorge y Soto L Madrid, Miguel Angel, Justicia Alternativa y el Sistema Acusatorio (México: SEGOB, 2013)

Consedine, Jim. Restorative justice: Healing the effects of crime. Lyttelton: Ploughshares Publications, 1995.

Ferreira Costa, Carolina. "As ilusões do paradigma punitivo e as novas perspectivas de solução de conflitos: a justiça restaurativa como caminho possível à crise do sistema penal brasileiro." Revista de Estudios Jurídicos UNESP 14, no. 19 (2011). 
Pesqueira Leal, Jorge. "Conclusiones del foro de análisis dialéctico sobre Justicia Penal Restaurativa y salidas alternas al Juicio Oral". Acapulco, Guerrero, México, Marzo 2010.

Román, Pizón, Edmundo, y Pesqueira, Leal, Jorge. "Manifiesto de Guerrero". En I Congreso Nacional de Justicia Restaurativa y Oralidad. Acapulco, Guerrero, 2010.

Van Ness, Daniel W., and Karen Heetderks Strong. Restoring justice: An introduction to restorative justice. Access Online via Elsevier, 2010.

Zernova, Margarita, "Restorative Justice Ideas, Values and Debates", Internet Journal of Criminology (2011 [citado el 25 de Noviembre del 2013]) disponible en:

http://www.internetjournalofcriminology.com/Zernova_Book_Review_Restorativ e_Justice_IJC_Feb_2012.pdf

Zehr, Howard. The little book of restorative justice. Intercourse, PA: Good Books, 2002. 